Article

\title{
Natural Antioxidant Control of Neuropathic Pain-Exploring the Role of Mitochondrial SIRT3 Pathway
}

\author{
Sara Ilari ${ }^{1}$, Luigino Antonio Giancotti ${ }^{2}{ }^{-}$, Filomena Lauro ${ }^{2}$, Micaela Gliozzi ${ }^{1}$, \\ Valentina Malafoglia ${ }^{3}$, Ernesto Palma ${ }^{1}{ }^{(D}$, Marco Tafani $^{4}\left(\mathbb{D}\right.$, Matteo Antonio Russo $^{5}$, \\ Carlo Tomino ${ }^{6}$, Massimo Fini ${ }^{6}$, Daniela Salvemini ${ }^{2}$, Vincenzo Mollace ${ }^{1}$ \\ and Carolina Muscoli ${ }^{1, *}$ \\ 1 Department of Health Sciences, Institute of Research for Food Safety \& Health (IRC-FSH), \\ University “Magna Graecia” of Catanzaro, 88201 Catanzaro, Italy; sara.ilari@hotmail.it (S.I.); \\ micaela.gliozzi@gmail.com (M.G.); palma@unicz.it (E.P.); mollace@libero.it (V.M.) \\ 2 Department of Pharmacology and Physiology, Henry and Amelia Nasrallah Center for Neuroscience, \\ Saint Louis University School of Medicine, St. Louis, MO 63104, USA; luigi.giancotti@health.slu.edu (L.A.G.); \\ milena.lauro@health.slu.edu (F.L.); daniela.salvemini@health.slu.edu (D.S.) \\ 3 Institute for Research on Pain, ISAL Foundation, 47922 RN Torre Pedrera, Italy; \\ valentinamalafoglia@yahoo.it \\ 4 Department of Experimental Medicine, University of Rome "Sapienza", 00161 Rome, Italy; \\ marco.tafani@uniroma1.it \\ 5 MEBIC Consortium, San Raffaele Rome Open University, 00163 Rome, Italy; matteo.russo@sanraffaele.it \\ 6 Scientific Direction, IRCSS San Raffaele Pisana, 00163 Rome, Italy; carlo.tomino@sanraffaele.it (C.T.); \\ massimo.fini@sanraffaele.it (M.F.) \\ * Correspondence: muscoli@unicz.it; Tel.: +39-09613695732
}

Received: 30 September 2020; Accepted: 6 November 2020; Published: 9 November 2020

\begin{abstract}
Neuropathic pain is a chronic painful disease. Data have shown that reactive oxygen species (ROS) are implicated in chronic pain. Particularly, the enhanced ROS production alters the mitochondrial genome and proteome through the accumulation of lipid peroxidation products, such as 4-hydroxynonenal (4-HNE) and malondialdehyde (MDA). Sirtuin 3 (SIRT3) is a mitochondrial protein and its activity can reduce ROS levels by modulating key antioxidant enzymes, such as manganese superoxide dismutase (MnSOD). Here, we evaluated the role of SIRT3 in the maintenance of basal levels of ROS in a model of chronic constriction injury (CCI) of the sciatic nerve and the protective effects of a natural antioxidant, the bergamot polyphenolic fraction (BPF). Rats were exposed to CCI of the sciatic nerve in the presence or absence of $\mathrm{BPF}(25-75 \mathrm{mg} / \mathrm{kg})$. Level of acetylation, post-translational modulation on cysteine residues of proteins by HNE and SIRT3 activation, were detected in the spinal cord through western blotting, WES methodology and enzymatic assays. Our results reported that SIRT3 carbonylation and therefore its inactivation contributes to mitochondrial MnSOD hyperacetylation during CCI induced neuropathic pain in rats. In particular, we have demonstrated a close relation between oxidative stress, hyperalgesia, allodynia and sirtuins inactivation reverted by BPF administration.
\end{abstract}

Keywords: neuropathic pain; natural antioxidants; polyphenols; sirtuin 3; mitochondria; oxidative stress; spinal cord 


\section{Introduction}

Neuropathic pain is the most common clinical manifestation of peripheral neuropathy, resulting from diabetes, infections, nerve-related diseases and drugs; the prevalence of neuropathic pain is almost $19 \%$ of adult Europeans [1-4].

Peripheral nerve injuries are often the cause of the onset of persistent pain indicating a disease progression process, which can result in chronic pain [2]. Knowledge on the processes underlying neuropathic pain has evolved in recent years indicating a complex scenario in which multiple cellular and molecular players contribute to the development of the disease [2]. Increasing evidence suggests that the action of oxidative species may be critical to the pain of several etiologies including neuropathic pain [5-8].

It is well known that neuropathic pain produces thermal hyperalgesia and allodynia contributing to the development of reactive oxygen and nitrogen species (ROS; RNS) and cytokines, able to carry out oxidative, nitrosative and nitrative activities implicated in persistent pain states [9-13]. Abnormalities of inflammatory cytokine profile play an important role in neuropathic pain. A recent study [14] has shown that the abnormal activation of pro-inflammatory cytokines, such as TNF $\alpha$ and ILB, produced in both spinal cord and in medial prefrontal cortex of a rat model of Spared Nerve Injury, were responsible of Chronic Neuropathic Pain - related anhedonia [14].

In addition, over-production of nitroxidative species results in oxidative stress and may lead to irreversible functional damages, including cancer, diabetes, obesity, osteoarthritis [15-17].

Oxidative stress causes an alteration in mitochondrial dynamics leading, in turn, to the increase of ROS production, responsible for the dysfunctional mitochondria [18-23]. Numerous studies have demonstrated new mitochondrial regulation pathways in cellular oxidative stress and inflammatory signaling [9,24-26]. In particular, it has been shown that oxidative damage, through the accumulation of lipid peroxidation (4-hydroxynonenal (4-HNE), malondialdehyde (MDA), is responsible for post-translational modification and inactivation of key mitochondrial proteins, by altering mitochondrial activities in cardiovascular, neurodegenerative diseases and pain [21,27-32].

Recent data have indicated that mitochondrial dysfunction is one of the causes of neuropathic pain contributing to the disease progression $[33,34]$. Considering that approximately $20 \%$ of mitochondrial proteins are acetylated, acetylation/deacetylation appears as a pivotal regulator mechanism for mitochondrial proteome function [35].

Interestingly, Sirtuin 3 (SIRT3) can improve the ability of mitochondria to reduce ROS levels and protect against oxidative stress by regulating the activity of key antioxidant enzymes, such as manganese superoxide dismutase (MnSOD) [19,36-39]; indeed, SIRT3 is a mitochondrial enzyme that regulates the mitochondrial lysine acetylation in an NAD+-dependent manner [38].

Moreover, SIRT3 plays an important role in a wide range of biological activities such as energy homeostasis, apoptosis, inflammation and it can be used for protection against cardiovascular diseases and heart failure [40-42]. Also, SIRT3 deacetylation targets are implicated in the oxidative stress response [40-42], regulating acetylation and activity of key antioxidant enzymes to prevent oxidative stress $[43,44]$. Several studies have described pharmacological approaches leading to SIRT3 activation, for the treatment of diseases associated with SIRT3 deficiency [45] and several aging-related conditions, such as type 2 diabetes, most persistent diseases of rheumatologic interest or chronic lymphocytic leukemia $[45,46]$. The mechanism by which SIRT3 regulates the antioxidant-driven redox signaling is still unclear and represents an interesting area of research.

Our recent data revealed the involvement of mitochondrial SIRT3 during carrageenan-induced inflammatory pain [19]. We spotted as SIRT3 inactivation, induced by oxidative stress condition, could be responsible for MnSOD inactivation with continuous ROS production that leads, in turn, to mitochondrial dysfunction [19]. Removal of free radicals by natural or synthetic antioxidants blocks protein post-translational modification, attenuating the observed biochemical changes and preventing the development of pain [32,47-49]. 
In this regard, it has been observed that polyphenols, such as resveratrol, bergamot, hydroxytyrosol and oleuropein, have strong antioxidant and anti-inflammatory properties [19,21,32,50,51]. Moreover, these substances can activate sirtuins directly or indirectly in several animal models [50]. Therefore, modulation of glutamatergic transmission and sirtuins' activation by polyphenols could be considered as new strategies in chronic pain therapy.

Studies showed that bergamot (in particular the bergamot polyphenolic fraction; BPF) has a higher concentration of polyphenols compared to other citrus fruits; in fact, it contains 5 main flavonoids namely neoeriocitrin, naringin, neohesperidin, melitidin and brutieridin [32,52-54].

Particularly, bergamot polyphenols have hypolipemic and hypoglycemic activity: the oral assumption, for 30 days, reduces total cholesterol, LDL (an effect also accompanied by elevation of HDL) and triglyceride levels in both rats and human patients [52].

The co-administration of morphine and BPF can be a good therapeutic approach for the treatment of chronic pain thanks to its ability to inhibit, in a dose-dependent manner, the development of tolerance preserving analgesic-morphine property [32].

Based on these data, here, we propose that, in the chronic constriction injury (CCI) model of neuropathic pain, SIRT3 modifications can alter mitochondrial homeostasis contributing to the insurgence and maintenance of pain.

\section{Materials and Methods}

\subsection{Animals}

8 weeks old males rats (Sprague-Dawley, 225-250 g, Envigo), were used according to the Italian regulations for animal protection in experimental and other scientific purposes (D.L. 26/2014), the European Economic Community regulations 2010/63/UE (authorization number 577-2016-PR) and the NIH Guideline on Laboratory Animal Welfare. The numbers of animals used are the minimum number necessary to achieve statistical significance at the $p<0.05$ as set forth by the International Society for the Study of Pain guidelines. Rats (2 per cage) were housed and preserved fixed temperature $\left(21 \pm 1^{\circ} \mathrm{C}\right)$ and humidity $(60 \pm 5 \%)$ conditions, allowed for food ad libitum, in a 12-hour light/12-hour dark cycle. Experiments were performed between 7:00 and 10:00 a.m. in a quiet room.

Natural antioxidant Bergamot polyphenolic fraction (BPF) was kindly provided by H\&AD (Herbal and Antioxidants Derivatives srl). Unless specified, all drugs were purchased from Sigma Aldrich and dissolved in saline (sodium chloride $0.9 \%$ ).

\subsection{Induction of Neuropathic Pain}

Chronic constrictive injury $(\mathrm{CCI})$ to the sciatic nerve of the right hind paw in rats was performed under general anesthesia, using the Bennett model [15]. Nociceptive thresholds were assessed before and after performing surgery, on days $0,3,7,10,14$ and 21 . Rats were sacrificed 14 or 21 days after the CCI; the dorsal half of the spinal cord lumbar region enlargement (L4-L5) was excised and immediately frozen in liquid nitrogen for subsequent analysis.

\subsection{Osmotic Pump Implantation}

Male Sprague Dawley rats, were lightly anesthetized with Zoletil and Ronpum (1:1; i.p.) and were subcutaneously implanted (in the inter-scapular region) with primed osmotic minipumps (Alzet), to deliver drugs or saline at $2.5 \mu \mathrm{L} / \mathrm{h}$ over 21 days. The concentrations of BPF and pregabalin resulted in a daily dose of $25-75 \mathrm{mg} / \mathrm{kg}$ and $10 \mathrm{mg} / \mathrm{kg}$ respectively. Mini pumps were filled according to manufacturer's specifications. The use of the osmotic pump ensures a continuous subcutaneously delivery of drugs avoiding intermittent periods of withdrawal. The integrity of the pump delivery system was re-examined at the end of each experiment when the spinal cords are collected. 


\subsection{Experimental Groups}

Animals were randomly assigned into the following groups:

- Sham group: Rats ( $n=15)$ subjected to a surgical procedure to expose the sciatic nerve without any ligation and treated with saline concurrently with surgery (day 0$)$, for 21 consecutive days.

- CCI group: Rats $(n=15)$ undergoing chronic constrictive injury (CCI) to the sciatic nerve and treated with saline (vehicle) concurrently with surgery (day 0 ), for 21 consecutive days.

- Drugs groups: Rats ( $n=15$ for each dose) subjected to CCI to the sciatic nerve and treated with different doses of BPF $(25 \mathrm{mg} / \mathrm{kg}$, $50 \mathrm{mg} / \mathrm{kg}$ or $75 \mathrm{mg} / \mathrm{kg})$ or pregabalin $(10 \mathrm{mg} / \mathrm{kg})$ concurrently with surgery (day 0 ), for 21 consecutive days.

The dose of the compounds has been chosen according with the bibliography [32,51,55].

\subsection{Behavioral Test}

Mechanical allodynia of the hind paw was measured by determining withdrawal thresholds to a calibrated series of von Frey filaments. The paw withdrawal threshold (PWT) was determined by sequentially increasing and decreasing the stimulus strength (the "up- and-down" method). Each rat was placed in a Plexiglas cage with a metal mesh floor and allowed to acclimate for $15 \mathrm{~min}$ before testing. The filaments were applied perpendicularly to the medial plantar surface of the paw in an ascending order of bending force sufficient to bend the microfilament. Each filament was applied three times and each application lasted for two seconds. A 30-sec interval was set between each application. A positive response was defined as the paw withdrawal threshold (PWT), when rats showed at least three withdrawal responses out of five times application to a filament [15].

Mechanical hyperalgesia was assessed using the Randall-Selitto analgesiometer (Ugo-Basile, Varese, Italy). An incremental pressure was applied on the dorsal surface of paws and the pressure that exhibited the first nociceptive response such as squealing and reflex movement was recorded as the pain threshold for injured rats. The stimulus was applied on the paw with a cut off pressure of $250 \mathrm{~g}$ to avoid injury and damage. Results are expressed as Paw-withdrawal threshold (PWT (g)).

Thermal hyperalgesia was evaluated by radiant heat paw withdrawal test as described by Hargreaves [56] and a cut off latency of $20 \mathrm{sec}$ was employed, in order to prevent tissue damage in non-responsive animals. Each rat was placed in a Plexiglas cage to acclimate for $15 \mathrm{~min}$ (Ugo-Basile, Varese, Italy). A mobile unit consisting of a high intensity projector bulb was positioned to deliver a thermal stimulus directly to an individual hind paw from beneath the chamber. The withdrawal latency period of paws was determined to the nearest $0.1 \mathrm{sec}$ with an electronic clock circuit and thermocouple. If the animal failed to respond by $20 \mathrm{sec}$ the test was terminated. Each point represents the delta change (sec) in withdrawal latency [withdrawal latency of left paw (contralateral paw) minus withdrawal latency of the right hind paw which received the chronic constrictive injury (CCI) to the sciatic nerve (ipsilateral paw)] at each time point. Results are expressed as Paw-withdrawal latency changes (sec).

\subsection{Tissue Preparation for Mitochondrial Extraction}

Lumbar spinal cord (L4-L6) tissues were homogenized with lysis buffer (250 mM Sucrose; $10 \mathrm{mM}$ Tris; $1 \mathrm{mM}$ ethylenediaminetetraacetic acid (EDTA); $1 \%$ protease inhibitor cocktail; $\mathrm{pH} 7.8$ ) at 1:3 w/v ratio. Extracts were centrifuged at $1000 \times g$ for $10 \mathrm{~min}$. and the obtained supernatant were re-centrifuged at $12,000 \times g$ for $15 \mathrm{~min}$. Lysis buffer ( $1 \%$ Triton; $1 \%$ protease inhibitor cocktail) was used to re-suspend the pellets. Protein concentration was detected using the Bicinchoninic Acid (BCA) protein assay (Pierce) after centrifugation at $10,000 \times \mathrm{g}$ for $10 \mathrm{~min}$ at $4{ }^{\circ} \mathrm{C}$.

\subsection{Immunoprecipitation and Western Blot Analysis}

Mitochondrial fractions were used for immunoprecipitation and western blot analysis. $50 \mu \mathrm{L}$ of protein A-sepharose 4B resin (Sigma, Milan, Italy, cat. P9424) was washed four times in PBS. 
Each wash was consisted by mixing fresh PBS with resin (beads) and then the collection of cleaned beads by centrifugation (14,000 rpm at $4{ }^{\circ} \mathrm{C}$ for $\left.1 \mathrm{~min}\right)$. After lysis Buffer (1\% Triton; 1:100 Protease inhibitor cocktail) re-suspension, cleaned resin was incubated with anti-SIRT3 antibody (1:1000; Cell Signaling, Milan, Italy) or anti-MnSOD (1:1000; Millipore, Milan, Italy), $\mathrm{O} / \mathrm{N}$ at $4{ }^{\circ} \mathrm{C}$, gently mixing. $250 \mu \mathrm{g}$ of tissue homogenate supernatant were incubated with pre-washed beads (4 time in PBS) $\mathrm{O} / \mathrm{N}$ at $4{ }^{\circ} \mathrm{C}$. After centrifugation, pellets were used for Sodium Dodecyl Sulphate - PolyAcrylamide Gel Electrophoresis (SDS-PAGE) analysis.

Western blot analyses of immunoprecipitated proteins and total lysates were performed using specific antibodies. Briefly, samples were loaded in $12 \%$ SDS-PAGE minigels and then electrophoretically transferred to nitrocellulose membranes.

Membranes were blocked ( $2 \mathrm{~h}$, room temperature) with $1 \%$ Bovine Serum Albumin (BSA)/1× TBS/0.1\% Tween-20. Membranes were incubated with rabbit polyclonal anti-Lys-Acetylated antibodies $\left(\mathrm{O} / \mathrm{N}, 4^{\circ} \mathrm{C}, 1: 1000\right.$; Cell Signaling, Milan, Italy), mouse monoclonal anti-4HNE antibodies $\left(\mathrm{O} / \mathrm{N}, 4{ }^{\circ} \mathrm{C}\right.$, 1:1000; R\&D Systems, Milan, Italy), rabbit polyclonal anti-SIRT3 antibodies $\left(\mathrm{O} / \mathrm{N}, 4^{\circ} \mathrm{C}, 1: 1000\right.$; Cell Signaling, Milan, Italt), rabbit polyclonal anti-MnSOD antibodies $\left(\mathrm{O} / \mathrm{N}, 4^{\circ} \mathrm{C}, 1: 1000\right.$; Millipore, Milan, Italy) or mouse monoclonal anti-Prohibitin antibodies $\left(\mathrm{O} / \mathrm{N}, 4^{\circ} \mathrm{C}, 1: 1000\right.$; Thermo Scientific, Milan, Italy). After washing with TBS/T, membranes were incubated with specific peroxidase-conjugated secondary antibody ( $1 \mathrm{~h}$, room temperature, 1:10000 dilution; Amersham, GE Healthcare, UK) and the complex was detected by an enhanced chemiluminescence detection system (ECL, Amersham, UK). Protein levels quantitation was then performed by densitometry using Image Quant 5.2 software by Molecular Dynamics.

\subsection{WES (Simple Western ${ }^{\mathrm{TM}}$ )}

Detection of 4-HNE adducts of histidine residues and total acetylation mitochondrial protein expression were determined using WES (Simple Western ${ }^{\mathrm{TM}}$ ) by Protein Simple $($ ). Protein Simple $\subset$ keeping the concept of western blot analysis, has changed the detection method. In fact, the Simple Western ${ }^{\mathrm{TM}}$ system uses capillary electrophoresis to identify and quantify a protein of interest. Simple Western assays are automated, capillary-based immunoassays. During this type of assay, protein samples are separated, immobilized and probed with target specific antibodies by automated steps.

Initially, the capillary was filled with separation and stacking matrix. Then, reagents (Dithiothreitol, DTT; Fluorescent 5X Master Mix, Biotinylated Ladder) were prepared according to the protocol. Samples were diluted with 0.1X Sample Buffer (after dilution of 10X Sample Buffer 1:100 with water), combined with 5X Master Mix (1 MasterMix:4 Sample) to obtain $1.6 \mathrm{mg} / \mathrm{mL}$ and finally denatured. Antibodies were diluted to their optimal concentration (4-HNE 1:100 R\&D System; Lys-Acetylated antibodies 1:100; Cell Signaling; TOM20 1:16000 Santa Cruz, Heidelberg, Germany) and Luminol (150 $\mu \mathrm{L})$-Peroxide $(150 \mu \mathrm{L})$ mix was prepared. The plate was finally filled following the protocol scheme: $(5 \mu \mathrm{L}$ of Biotinylated Ladder, $5 \mu \mathrm{L}$ of Samples, $10 \mu \mathrm{L}$ of Wes Antibody Diluent II, $10 \mu \mathrm{L}$ of Primary Antibody, $10 \mu \mathrm{L}$ of Streptavidin-HRP, $10 \mu \mathrm{L}$ of Secondary Antibody and $10 \mu \mathrm{L}$ of Luminol-Peroxide Mix). Sample containing SDS, DTT and fluorescently labeled MW markers were taken from the plate and loaded into the capillaries. Voltage was applied across the capillaries to separate proteins in the sample. The capillaries were exposed to UV light, activating the proprietary linking chemistry and locking the separated proteins to the capillary wall. The capillaries were rinsed and immunoprobed for specific proteins with an HRP-labeled antibody. Luminol and peroxide were loaded into the capillaries to catalyze chemiluminescent light generation, which is captured by a charge-coupled device (CCD) camera. Simple Western ${ }^{\mathrm{TM}}$ systems captured data as a chemiluminescent image of the capillary. Images were analyzed by Compass software and could be presented as an electropherogram or as a lane.

\subsection{Malonylaldehyde Detection}

MDA quantification was performed through thiobarbituric acid reactive substances (TBARS) assay. In brief, tissue sample were added to a vial containing $10 \% \mathrm{NaOH}, 20 \%$ Acetic Acid and TBA. The vials were boiled at $90-100{ }^{\circ} \mathrm{C}$ and after $1 \mathrm{~h}$ the tubes were placed on ice to stop reaction. 
Before being transferred to a black 96-well microtiter plate samples were centrifugated $10 \mathrm{~min}$ at $1600 \times g$ at $4{ }^{\circ} \mathrm{C}$. The MDA-TBA adduct was measured fluorometrically at an excitation wavelength of $530 \mathrm{~nm}$ and emission wavelength of $550 \mathrm{~nm}$ using Infinite 200 microplate fluorometer (Tecan, Männedorf Switzerland).

\subsection{Determination of MnSOD Activity in the Spinal Cord}

MnSOD activity was detected using Superoxide Dismutase Assay kit (Cayman Chemical) following the manufacturer's protocol. The method uses tetrazolium salt to quantify superoxide radicals generated by xanthine oxidase and hypoxanthine. The standard curve was generated by using a quality-controlled SOD standard. The absorbance was monitored at 440-460 $\mathrm{nm}$ using a TECAN Sunrise Reader (Tecan, Männedorf, Switzerland). One unit of SOD is defined as the amount of enzyme needed to exhibit $50 \%$ dismutation of the superoxide radical. Enzymatic activity was presented as units/mL per milligram of total protein. The results were defined after triplicate analysis.

\subsection{Determination of Proteins Carbonylation in the Spinal Cord}

Protein carbonyl groups were detected using the Oxyblot protein oxidation Kit (Millipore) following the manufacturer's protocol. Briefly, carbonyl derivates of proteins were detected by reaction with 2,4-dinitrophenylhydrazine (DNPH) and the abundance of carbonyl protein groups was analyzed by Western Blot.

\subsection{SIRT3 Deacetylase Activity Assay}

SIRT3 deacetylase activity was determined using a SIRT3 Fluorimetric Activity Assay/Drug Discovery Kit (Biomol Research Laboratories) following the manufacturer's protocol. In brief, the mitochondrial extract was incubated with the Fluor de Lys substrate buffer and then incubated with Fluor de Lys Developer.

Infinite 200 microplate fluorometer (Tecan) were used to detect emitted light at $460 \mathrm{~nm}$, after excitation at $360 \mathrm{~nm}$.

\subsection{Statistical Analysis}

Data are presented as means \pm SEM for $n$ animals. Time course statistical analysis were performed via two-way repeated measures of variance (ANOVA) with Bonferroni comparisons.

After one-way ANOVA analysis, Tukey test was used for all remaining data. A threshold of 0.05 was considered for statistical significance. GraphPad Prism (v8.00; GraphPad Software, Inc, San Diego, CA, USA) was used for all the analysis.

\section{Results}

\subsection{Natural Antioxidant Treatment Reduces Experimental Pain-Associated Behaviour in CCI Rats}

The Chronic Constriction Injury (CCI) model of peripheral nerve provides a model system to investigate the effectiveness of potential therapeutic agents to modify chronic neuropathic pain. In rats, the CCI of the sciatic nerve leads to debilitating symptoms, such as spontaneous pain, hyperalgesia, allodynia and dysesthesia/paresthesia. Here, we observed that CCI causes a significant reduction in both mechanical withdrawal thresholds and thermal withdrawal latencies of the ipsilateral hind paw, indicating the presence of mechanical and thermal pain behavior as measured employing the Von Frey and Randall-Selitto test and the Hargreaves method respectively (Figure 1A-C). Injection of vehicle (saline) did not change the mechanical withdrawal threshold or thermal withdrawal latency (Figure 1A-C). No effects on contralateral paw withdrawal were found (Supplementary Figure S1). 
A

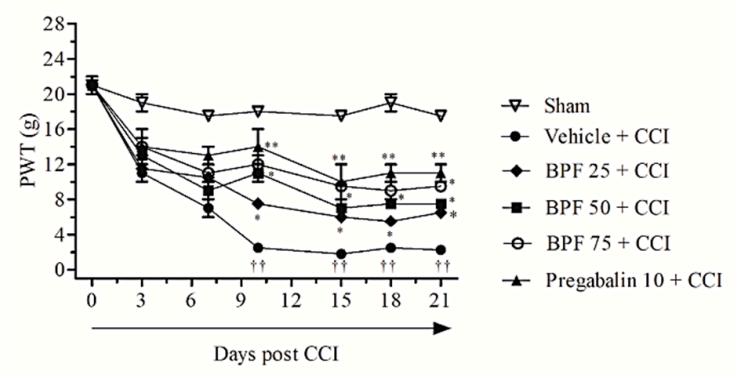

$\mathrm{B}$

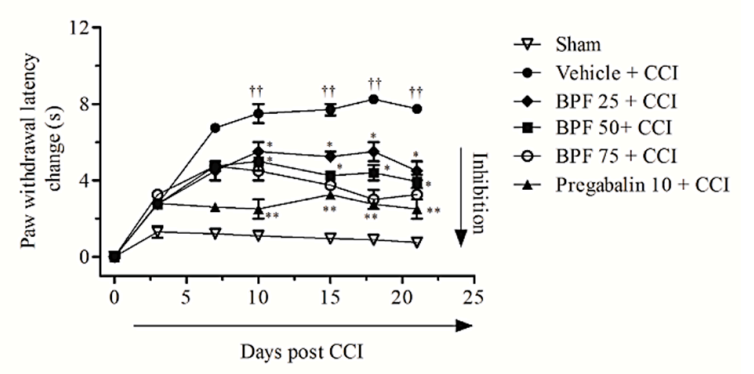

$\mathrm{C}$

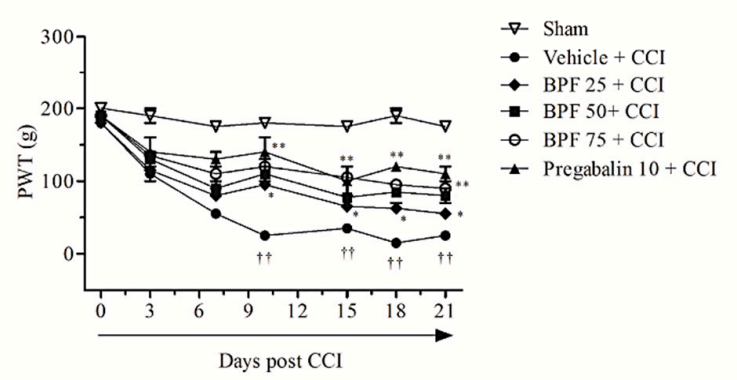

Figure 1. Effects of treatment with bergamot polyphenolic fraction (BPF) on allodynia and hyperalgesia after inducing Chronic Constriction Injury (CCI) in rats. In rats with CCI, subcutaneous infusion of BPF $(25-75 \mathrm{mg} / \mathrm{kg}$ ) or pregabalin $(10 \mathrm{mg} / \mathrm{kg})$, concurrently with surgery (day 0$)$, attenuated the development of mechano-allodynia (A), thermal hyperalgesia (B) and mechano-hyperalgesia (C) assessed over a 21 days period. Data are expressed as mean \pm SEM for 15 rats in each group. ${ }^{*} p<0.05$; ${ }^{* *} p<0.005$ versus vehicle + CCI, ${ }^{++} p<0.05$ versus sham.

Subcutaneous infusion of BPF $(25-75 \mathrm{mg} / \mathrm{kg})[32,51]$ by minipumps, concurrently with surgery (day 0 ) up to 21 days significantly modified, in a dose dependent manner, nociceptive parameters associated with time as follows: a significant enhancement in the mechanical withdrawal threshold and thermal withdrawal latencies were produced in the presence of BPF $(25-75 \mathrm{mg} / \mathrm{kg})$ starting from day 10 post injury up to day 21. Subcutaneous infusion of pregabalin $(10 \mathrm{mg} / \mathrm{kg}$ [55], concurrently with surgery (day 0)) by minipumps, over the same timeframe, showed the same efficacy (Figure 1A-C). The drugs administration by minipump is essential ensure a continuous subcutaneously delivery of BPF or pregabalin avoiding intermittent periods of withdrawal.

3.2. CCI-Induced Hyperalgesia and Allodynia are Associated with an Increase of Lipid Peroxidation Products and Post-Translational Modification of Mitochondrial Proteins

CCI-induced neuropathic pain development corresponds to the increase of the level of spinal malondialdehyde (MDA) (Figure 2A,B) and 4-hydroxynonenal (4-HNE) (Figures 3 and 4, Supplementary Figure S2) either 14- and 21-days post injury.

These effects were attenuated, at the level of the spinal cord (L4-L5), by treatment with BPF at $50 \mathrm{mg} / \mathrm{kg}$ (intermediate dose with an antioxidant effect similar to the effect due to the highest dose we used) (Figures 2-4 and Figure S2).

To measure the impairment of spinal mitochondrial protein due to oxidative stress through 4-HNE production, the carbonylation level of mitochondrial proteins and SIRT3 was analyzed by derivatizing immunoprecipitated SIRT3 with 2,4-dinitrophenyl hydrazine (DNPH). We observed an increase of mitochondrial carbonylated proteins (Figure 5A,B) and in particular SIRT3 carbonylation, either 14and 21-days post CCI (Figure 6A,B). 
The attenuation of mechanical and thermal hyperalgesia by BPF $(50 \mathrm{mg} / \mathrm{kg})$ is associated with a reduction of post-translational carbonylation of total mitochondrial proteins in the spinal cord (Figure 5A,B).

Furthermore, a relatively low level of carbonylation on SIRT3 in sham animals has been demonstrated (Figure 6). The CCI procedure induced an increase of SIRT3 carbonylation (Figure 6A,B) either 14 and 21 days post injury and the treatment with BPF $(50 \mathrm{mg} / \mathrm{kg})$ led to a significant reduction of SIRT3 carbonylation adducts (Figure 6A,B).

A

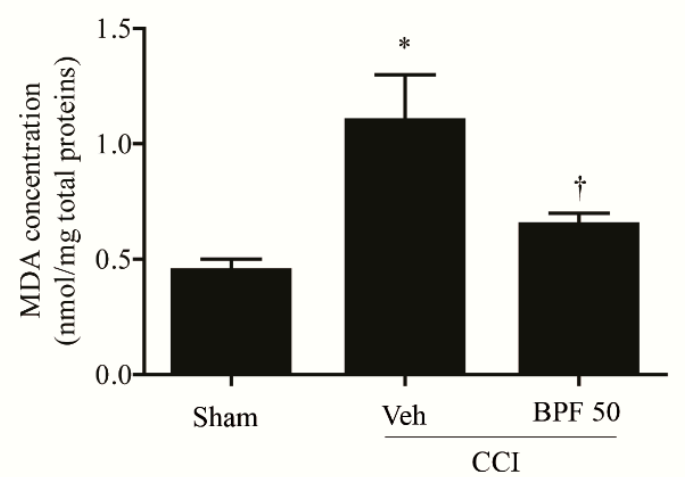

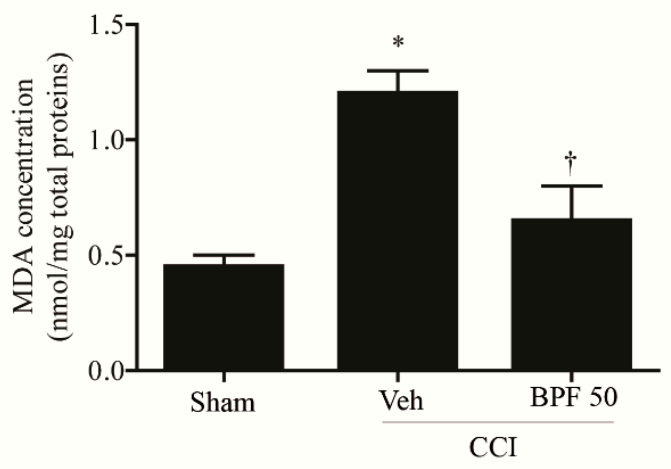

Figure 2. Malondialdehyde is associated with an increase of oxidative stress during neuropathic pain. Spinal malondialdehyde (MDA)indicates the presence of oxidative stress during chronic pain either 14 days (A) and 21 days (B) post injury. CCI rats showed a significant level of MDA either 14and 21-days post injury. Subcutaneous infusion of BPF $(50 \mathrm{mg} / \mathrm{kg})$, concurrently with surgery (day 0 ), led to a significant reduction of these values. Results are expressed as mean \pm SEM for 6 rats. ${ }^{*} p<0.05$ compared to sham; ${ }^{\dagger} p<0.05$ compared to vehicle + CCI.

A

Sham Veh BPF 50

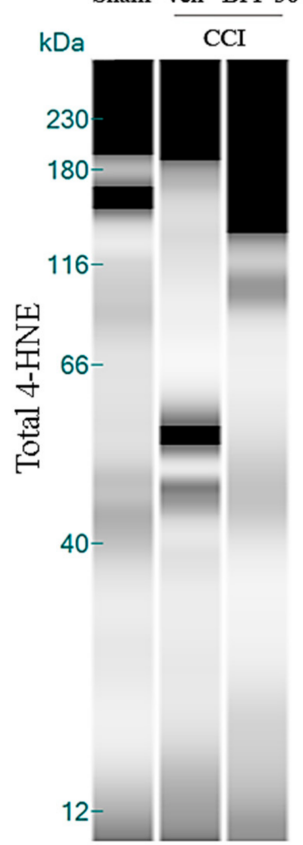

B

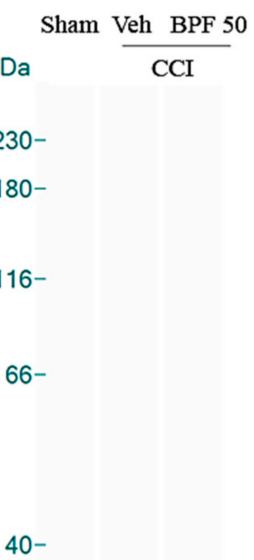

D

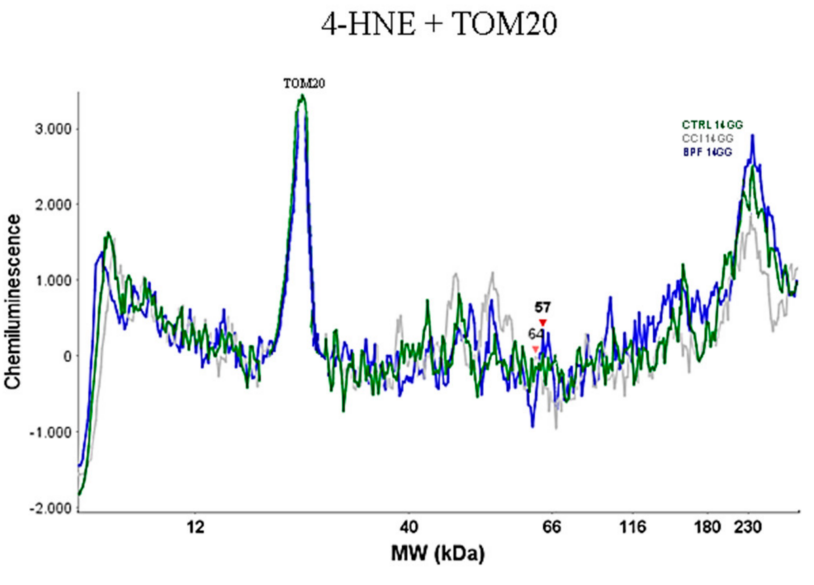

\section{TOM20}

12-

Figure 3. Cont. 


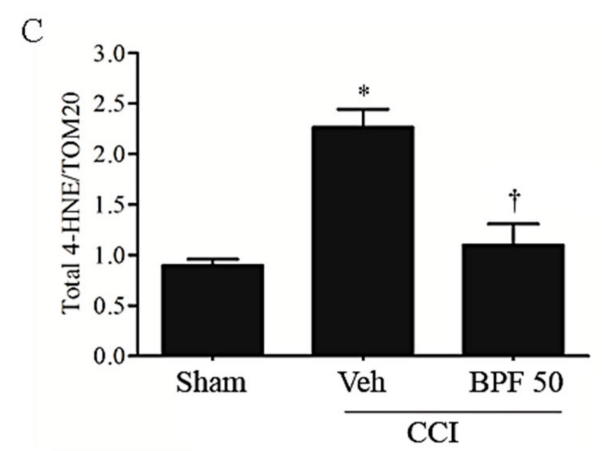

Figure 3. The development of hyperalgesia and allodynia coincided with an increase of 4-HNE level 14 days post injury. (A) CCI rats showed a significant production of 4-HNE in spinal cord 14 days post injury as measured by Simple Western (WES) methodology. Infusion of BPF (50 mg/kg), concurrently with surgery (day 0), showed a significant reduction of these values. (B) No difference for TOM20 expression was detected among the lanes in these conditions. (A,B) Lanes and (D) electropherogram are representative of results from 6 different animals. (C) Densitometric analyses of all animals per groups are reported. Results are expressed as mean \pm SEM for 6 rats. ${ }^{*} p<0.05$ versus sham; ${ }^{\dagger} p<0.05$ versus vehicle $+\mathrm{CCI}$.

It is known that the carbonylation reaction alters the function of many proteins and may play a role in regulating SIRT3 activity [19]. We demonstrated that once carbonylated, mitochondrial SIRT3 is inactivated, losing its ability to deacetylate either 14 or 21 days after injury (Figure 7A,B); treatment of rats with BPF inhibited SIRT3 carbonylation, preventing its inactivation (Figure 7A,B).

A

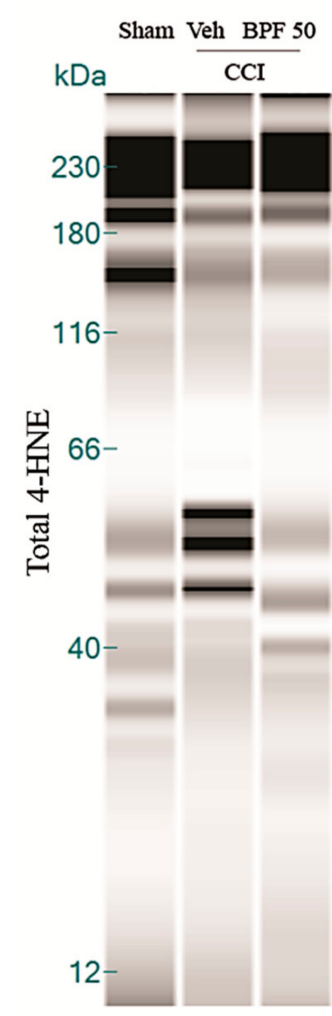

B

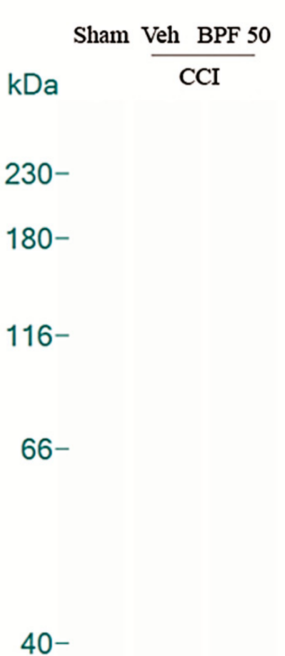

$40-$
$\mathrm{D}$

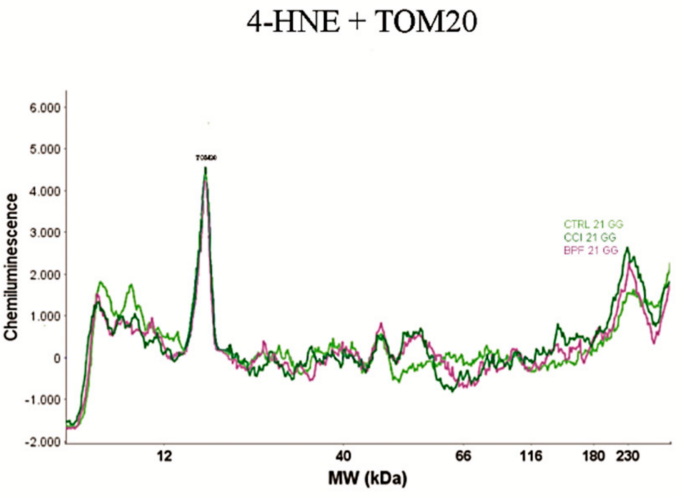

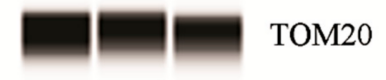

$12-$

Figure 4. Cont. 
C

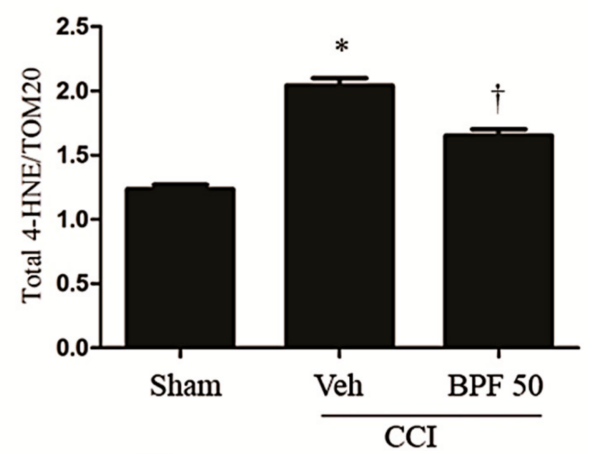

Figure 4. The development of hyperalgesia and allodynia coincided with an increase of 4-HNE level 21 days post injury. (A) CCI rats showed a significant production of 4-HNE in spinal cord 21 days post injury as measured by WES methodology. Subcutaneous infusion of BPF (50 mg/kg), concurrently with surgery (day 0), showed a significant reduction of these values. (B) No difference for TOM20 expression was detected among the lanes in these conditions. $(\mathbf{A}, \mathbf{B})$ Lanes and (D) electropherogram are representative of results from 6 different animals. (C) Densitometric analyses of all animals per groups are reported. Results are expressed as mean \pm SEM for 6 rats. ${ }^{*} p<0.05$ versus sham; ${ }^{\dagger} p<0.05$ versus vehicle + CCI.

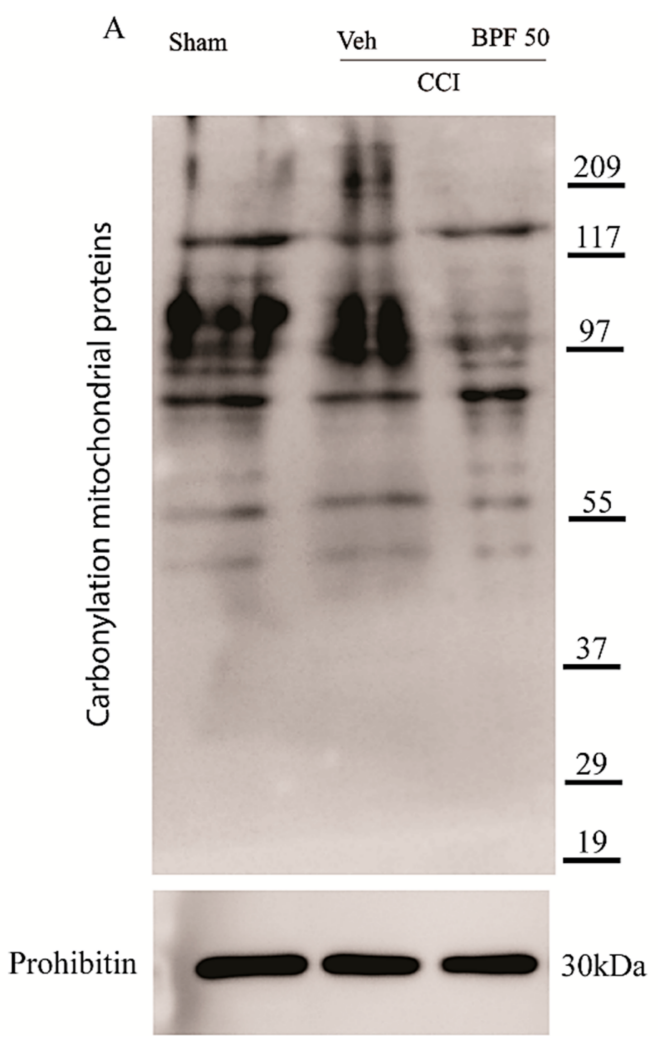

B
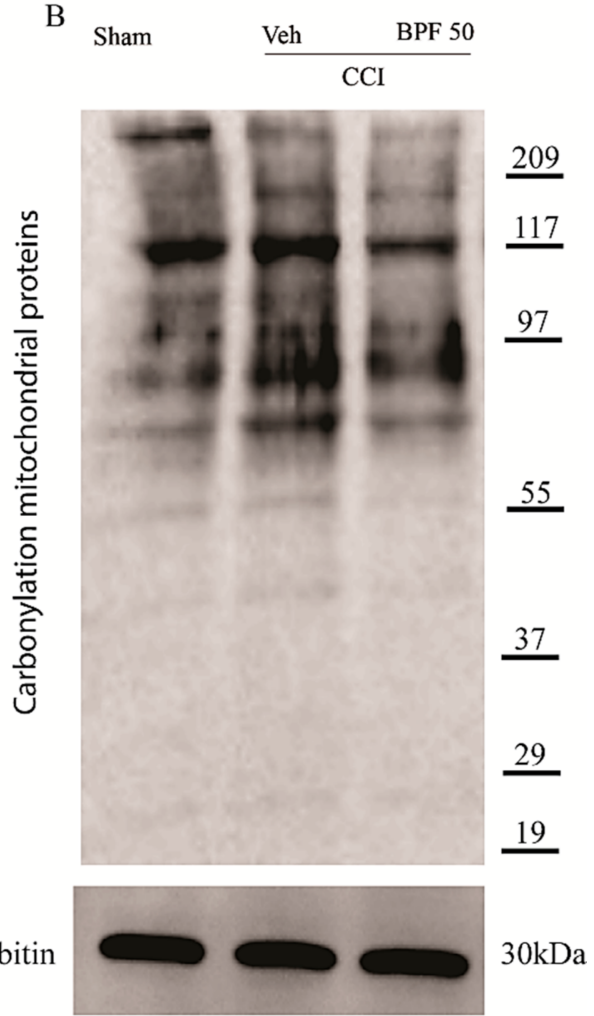

Figure 5. Cont. 

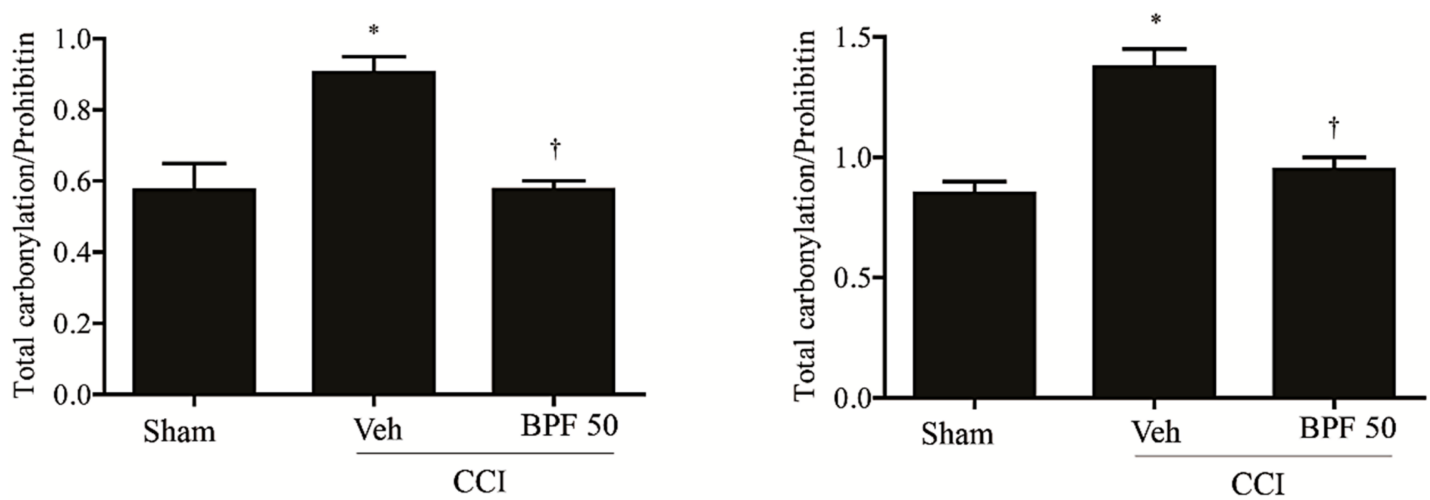

Figure 5. The increase of 4-HNE level cause carbonylation of mitochondrial proteins. High 4-HNE levels induced carbonylation of mitochondrial proteins either 14 days (A) and 21 days (B) post injury in CCI-only rats. Subcutaneous infusion of BPF $(50 \mathrm{mg} / \mathrm{kg})$, concurrently with surgery (day 0), prevented mitochondrial proteins carbonylation. In these conditions, prohibitin expression appeared statistically the same among groups. Gels are representative of results from 6 animals. Densitometric analyses of all animals per groups are reported. Results are expressed as mean \pm SEM for 6 rats. ${ }^{*} p<0.05$ compared to sham; ${ }^{\dagger} p<0.05$ compared to vehicle + CCI.
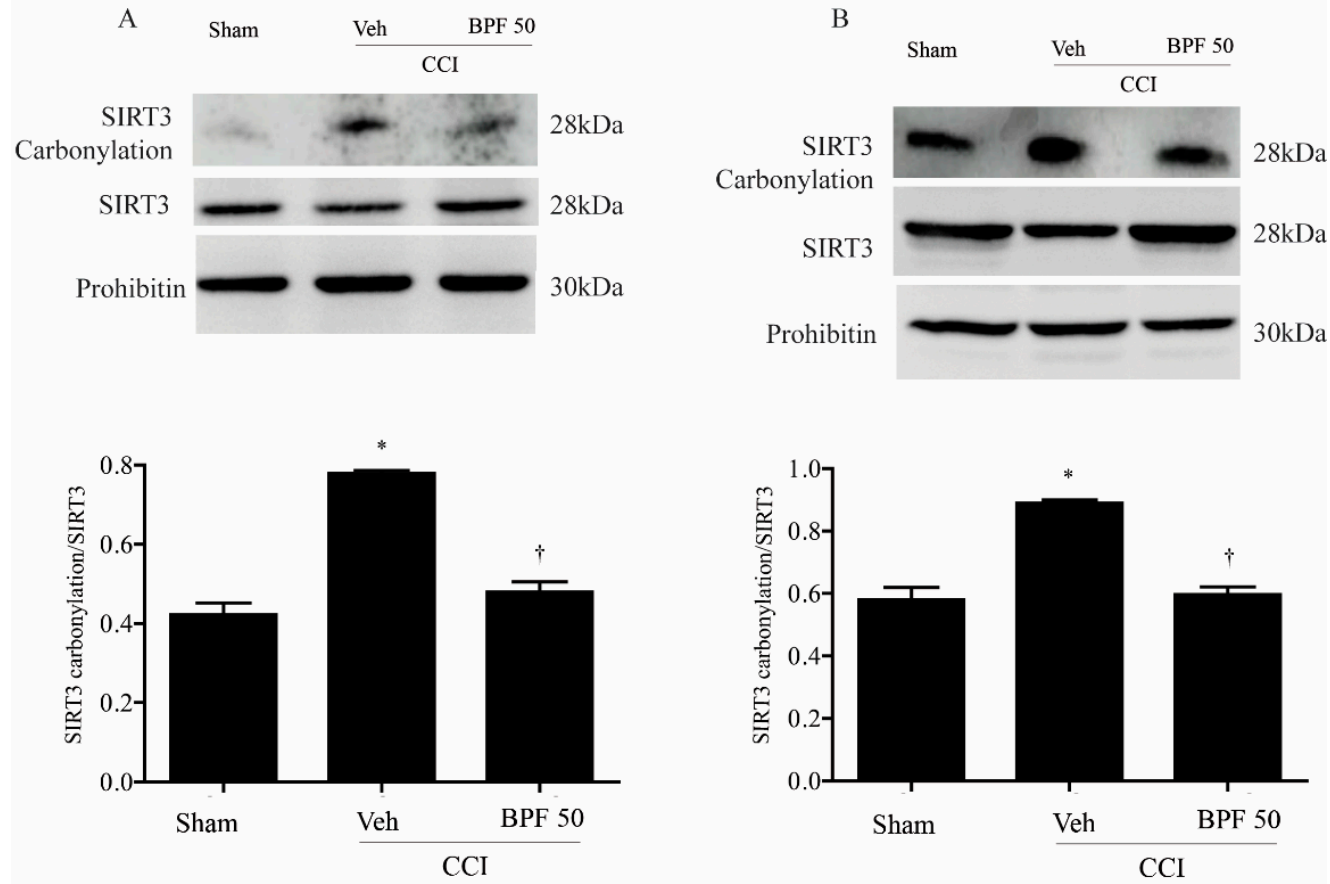

Figure 6. The development of hyperalgesia cause carbonylation of SIRT3 14 days post injury. Chronic constriction injury of the sciatic nerve (CCI) led to significant carbonylation of mitochondrial SIRT3 14 days (A) and 21 days (B) post injury, as measured by immunoprecipitation and Western blot. Infusion of BPF (50 mg/kg), concurrently with surgery (day 0), prevented SIRT3 carbonylation. In these conditions, prohibitin expression was statistically the same among the lanes. Gels are representative of results from 6 animals. Densitometric analyses of all animals per groups are reported. SIRT3 and SIRT3 carbonylation were first normalized with prohibitin and then these values were used to obtain carbonylation/total SIRT3 ratio. Results are expressed as mean \pm SEM for 6 rats. ${ }^{*} p<0.05$ compared to sham; ${ }^{\dagger} p<0.05$ compared to vehicle + CCI. 
A

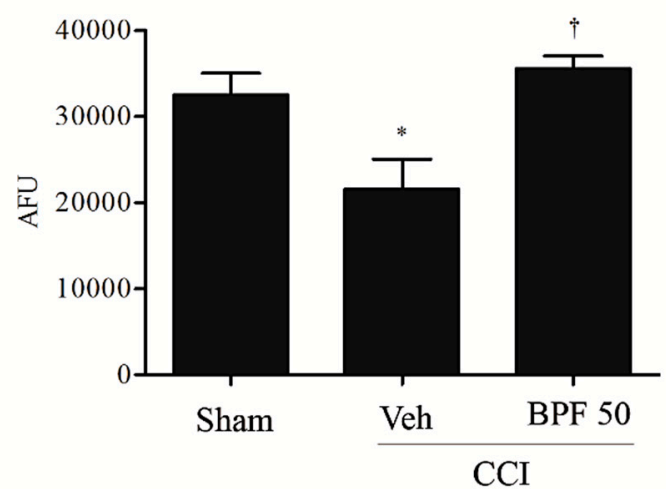

B

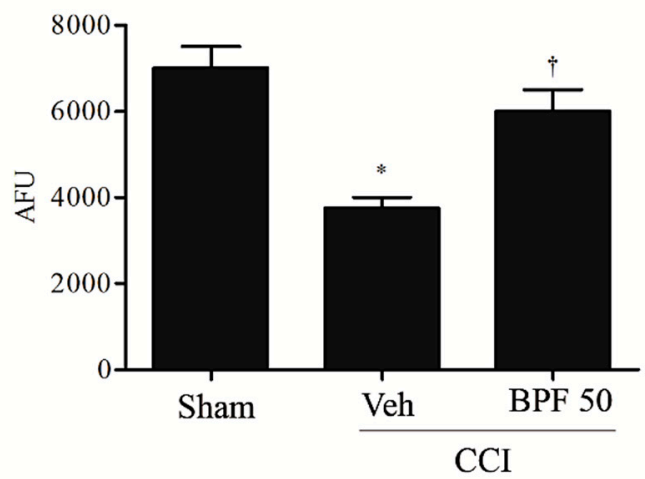

Figure 7. Carbonylation on SIRT3 is linked to inactivation of its biological function. Carbonylation and SIRT3 enzymatic activities intimately linked. In fact, animals with CCI, in comparison with sham group, presented low levels of SIRT3 activity either 14 days (A) and 21days (B) post injury as shown by western blotting results. Infusion of BPF $(50 \mathrm{mg} / \mathrm{kg})$, concurrently with surgery (day 0$)$, restored SIRT3 activity. Results are expressed as mean \pm SEM for 6 rats. ${ }^{*} p<0.05$ compared to sham; ${ }^{\dagger} p<0.05$ compared to vehicle $+\mathrm{CCI}$.

\subsection{Interaction between SIRT3 and Mitochondrial MnSOD Target Proteins}

SIRT3 is considered a crucial protein for oxidative stress regulation, controlling the expression and function of many other mitochondrial proteins via deacetylation $[43,57]$. In the Figures $5-7$, we showed that carbonylation plays a role in regulating SIRT3 activity. Its inhibition may alter the function of several mitochondrial proteins: in the Figure 8; Figure 9, we observed a dramatic increase of mitochondrial protein acetylation in the spinal cord (L4-L5) of animals receiving CCI to the sciatic nerve, while rats treated with BPF $(50 \mathrm{mg} / \mathrm{kg}$ ) reduced the acetylation of mitochondrial proteins (Figure 8, Figure 9 and Supplementary Figure S3).

In particular, it is well known that the main targets of SIRT3 is the MnSOD which detoxifies the radicals generated in the mitochondrial respiratory chain $[38,58]$. In this regard, we observed an increase in MnSOD acetylation levels either 14 or 21 days after CCI (Figure 10), at the same time as SIRT3 inactivation.

This event is associated with the inhibition of MnSOD activity (Figure 11). Treatment with BPF (50 mg/kg), most probably, prevented MnSOD acetylation restoring its activity (Figure 11). 
A

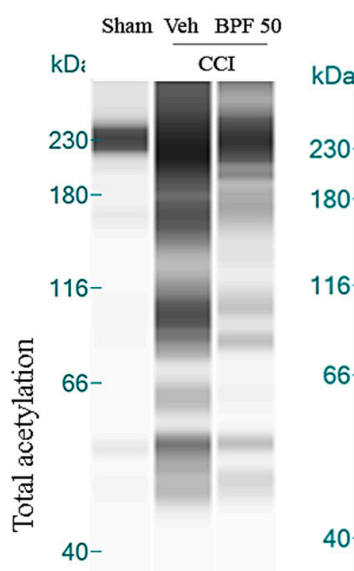

$12-$

B
Sham $\frac{\text { Veh BPF } 50}{\text { CCI }}$

$230-$

$180-$

116-

66-

40-

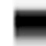

$12-$

C

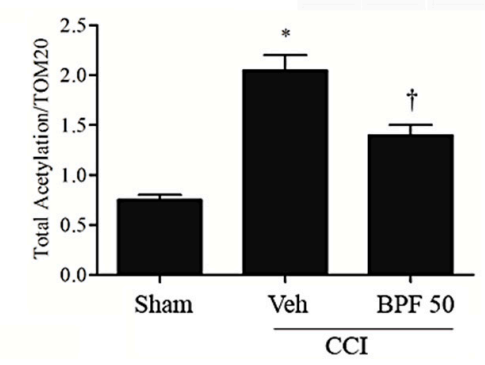

D

Total acetylation + TOM20

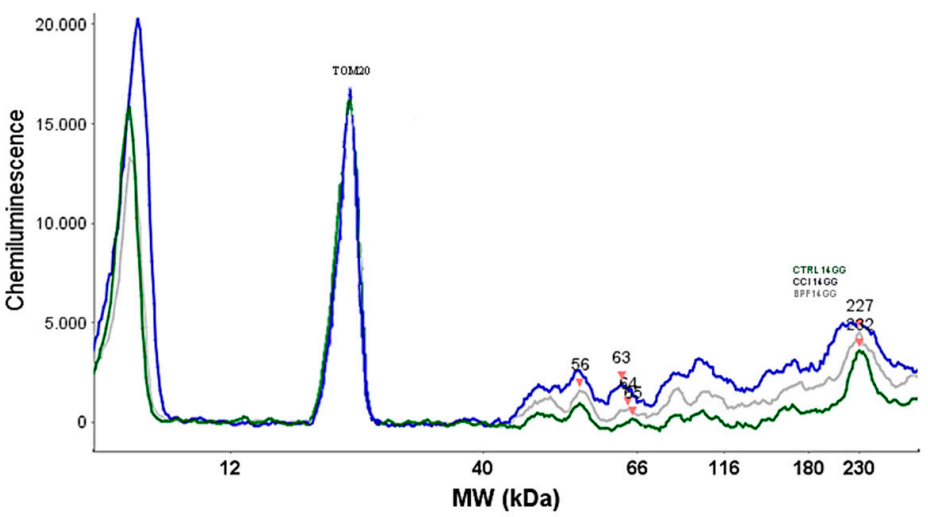

Figure 8. The inhibition of SIRT3 induces acetylation on mitochondrial proteins 14 days post injury. (A) Inactivation of SIRT3 led to significant acetylation of mitochondrial proteins 14 days post injury as shown by WES methodology. Subcutaneous infusion of BPF $(50 \mathrm{mg} / \mathrm{kg})$, concurrently with surgery (day 0), prevented mitochondrial proteins acetylation. (B) No difference for TOM20 expression was detected among the lanes in these conditions. (A,B) Lanes and (D) electropherogram are representative of results from 6 animals. (C) Densitometric analyses of all animals per groups are reported. Results are expressed as mean \pm SEM for 6 rats. ${ }^{*} p<0.05$ versus sham; ${ }^{+} p<0.05$ versus vehicle + CCI. 
A

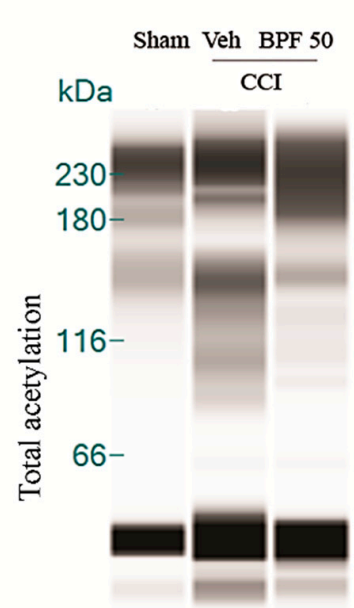

$40-$
B

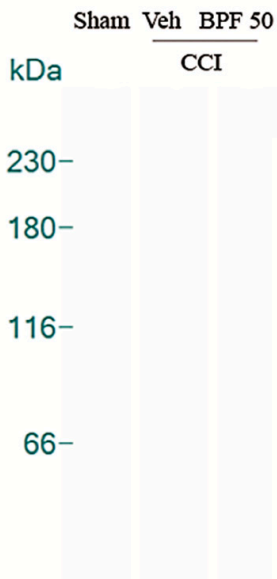

$40-$
D

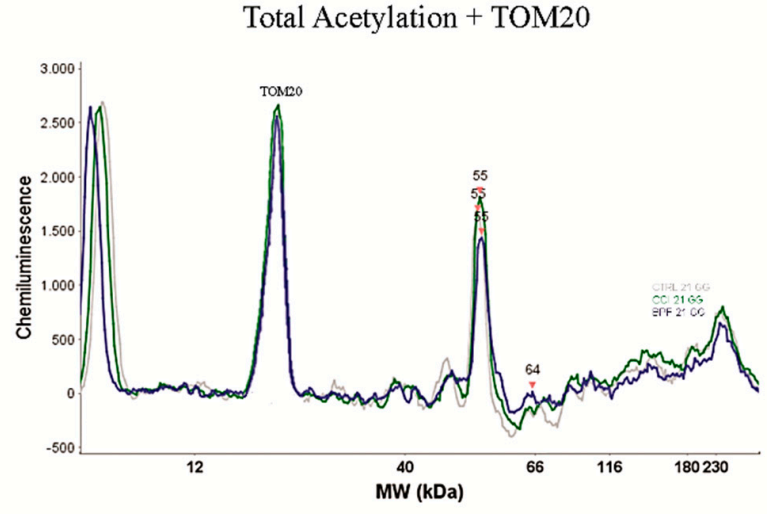

$12-$

12-

$\mathrm{C}$

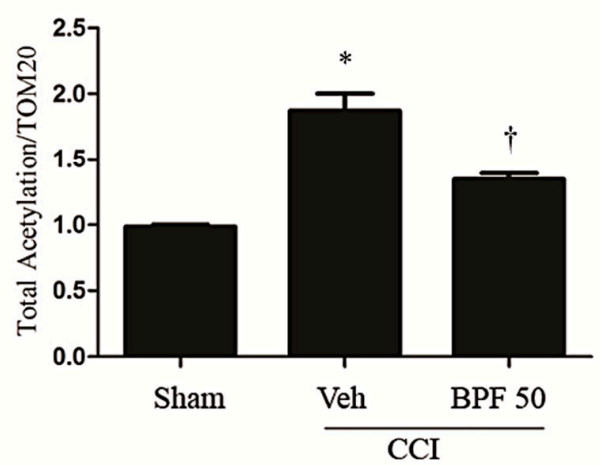

Figure 9. The inhibition of SIRT3 induces acetylation on mitochondrial proteins 21 days post injury. (A) Inactivation of SIRT3 led to significant acetylation of mitochondrial proteins either 21 days post injury as shown by WES methodology. Subcutaneous infusion of BPF (50 mg/kg), concurrently with surgery (day 0), prevented mitochondrial proteins acetylation. (B) No difference for TOM20 expression was detected among the lanes in these conditions. (A,B) Lanes and (D) electropherogram are representative of results from 6 animals. (C) Densitometric analyses of all animals per groups are reported. Results are expressed as mean \pm SEM for 6 rats. ${ }^{*} p<0.05$ versus sham; ${ }^{\dagger} p<0.05$ versus vehicle + CCI. 

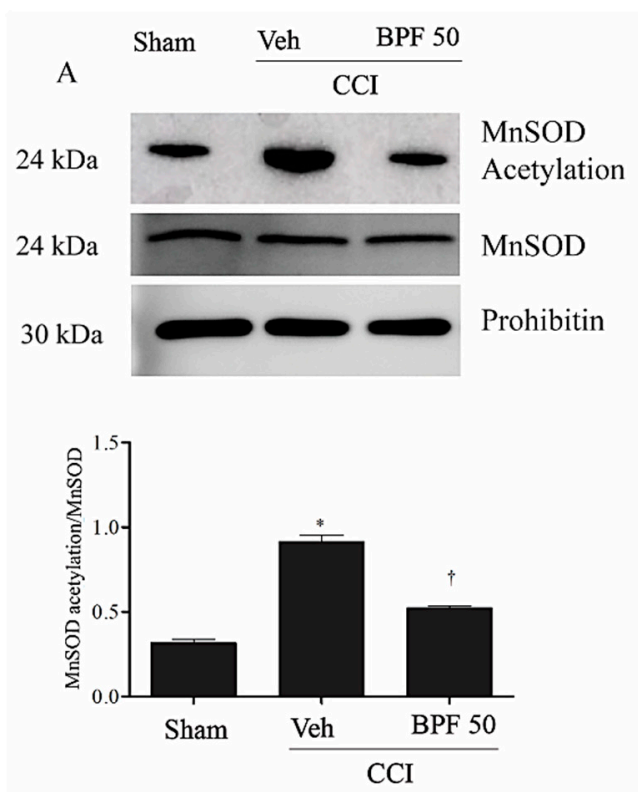
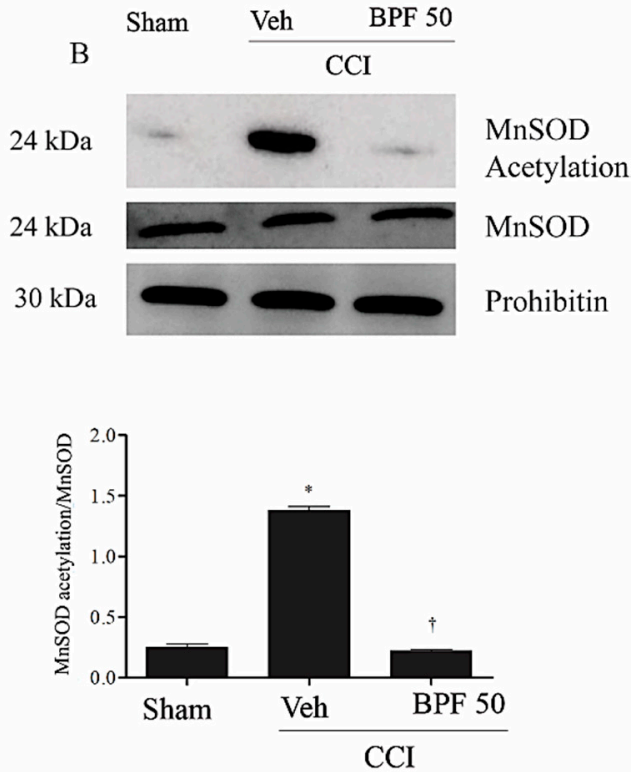

Figure 10. The inhibition of SIRT3 led to MnSOD acetylation. Inactivation of mitochondrial SIRT3 by the CCI injury induced mitochondrial MnSOD acetylation either 14 days (A) and 21 days (B) post injury as measured by immunoprecipitation. Subcutaneous infusion of BPF ( $50 \mathrm{mg} / \mathrm{kg})$, concurrently with surgery (day 0), prevented MnSOD acetylation. In these conditions, prohibitin or MnSOD expression was statistically the same among the lanes. Gels are representative of results from 6 animals. Densitometric analyses of all animals per groups are reported MnSOD and acetylated MnSOD were first normalized with prohibitin and then these values were used to obtain acetylated/total MnSOD ratio. Results are expressed as mean \pm SEM for 6 rats. ${ }^{*} p<0.05$ versus sham; ${ }^{\dagger} p<0.05$ versus vehicle $+\mathrm{CCI}$.

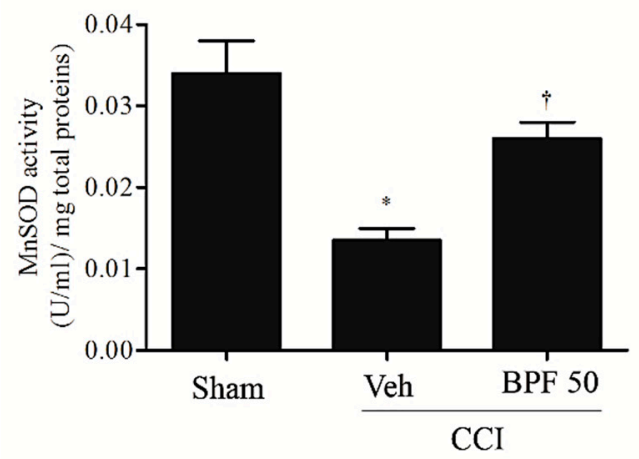

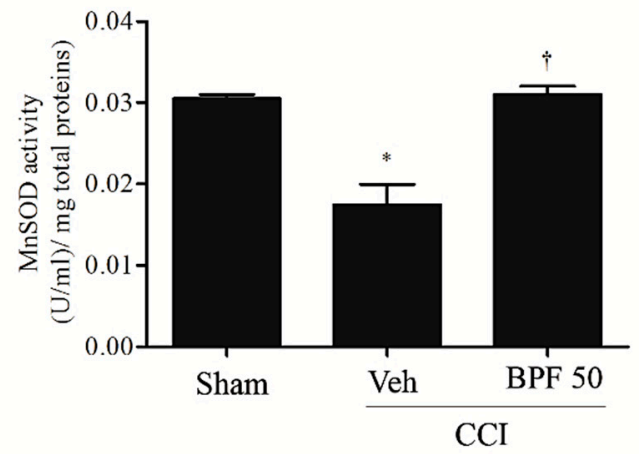

Figure 11. Acetylation on MnSOD is associated to inactivation of its biological function. MnSOD acetylation is intimately linked to inactivation of MnSOD enzymatic function either 14 days (A) and 21 days (B) post injury. In fact, when compared with sham group, CCI rats showed low levels of MnSOD activity. Subcutaneous infusion of BPF (50 mg/kg), concurrently with surgery (day 0), prevented mitochondrial proteins acetylation. Results are expressed as mean $\pm \mathrm{SEM}$ for 6 rats. ${ }^{*} p<0.05$ versus sham; ${ }^{\dagger} p<0.05$ versus vehicle + CCI.

\section{Discussion}

Chronic pain is one of the most serious public health problem. Although the huge amount of studies concerning this pathology, nowadays there is not a precise treatment for chronic pain [59]. Moreover, the lack of specific diagnostic tools makes chronic pain therapy really arduous [60,61] increasing the gap between preclinical and clinical results. 
Toxic agents, such as reactive oxygen species (ROS), are involved in the development and maintenance of various diseases, including neuropathic pain [20,23,48,49], regulating activation of N-methyl-d-aspartate (NMDA) receptor [62] and then leading to the development of hyperalgesia [20,48].

Considering that mitochondrial dysfunctions are linked to pain, the protection of mitochondrial functions against oxidative stress can be considered as a therapeutic strategy to alleviate or prevent chronic pain states [26,62-65].

The discovery of sirtuins (SIRTs) involvement in pain pathways and their dysfunctional modulation by free radical products, could be of great interest for the identification of new potential therapeutic targets for the management of the different etiologies of pain. Particularly SIRT3, already involved in the regulation of cellular energy metabolism, in cardiovascular diseases and in the control of apoptosis [42,66], has recently emerged as a novel regulator of mitochondrial metabolism and function too $[42,66]$.

In this study, we showed that the development of hyperalgesia and allodynia after CCI of the sciatic nerve in rats (Figure 1), was associated with the increase of MDA and 4-HNE levels (biochemical markers of lipid peroxidation and oxidative stress) and attenuated by treatment with BPF at $50 \mathrm{mg} / \mathrm{kg}$ (Figures 2-4). Moreover, during neuropathic pain induced by CCI, we showed an increase of SIRT3 carbonylation (Figure 6) and then its inactivation (Figure 7), responsible for the mitochondrial hyperacetylation event (Figures 8 and 9), blocked by treatment with BPF $(50 \mathrm{mg} / \mathrm{kg})$. Our data suggest that lipid peroxidation products play a key role in the generation of neuropathic pain and, taken together, these results show that free radicals and 4-HNE are important mediators of the induction of hyperalgesia and allodynia during chronic pain, via modulation of mitochondrial activities. This action was pharmacologically reverted through the utilization of antioxidants.

Oxidative/carbonyl stress-induced different effects on SIRT3, such as the decrease of its activity, responsible for acetylation of MnSOD (Figure 10). The consequent deactivation of this protective enzyme, enhancing hyperalgesia and allodynia, would lead to a vicious circle that could contribute to the neuropathic pain insurgence and maintenance.

Therefore, inhibition of SIRT3 carbonylation by polyphenols (Figure 6) could be beneficial for therapeutic intervention of chronic pain and hyperalgesia modulation, observed during neuropathic pain [19]. Numerous studies have now observed that polyphenols have antioxidant and anti-inflammatory properties and their ability to activate sirtuins, either directly or indirectly, has also been described in a variety of models [67-70].

Recently, the interest in natural antioxidants as pharmacological drugs, in several diseases, is increased [31,32] since their utilization could be considered as an alternative affordable approach against the insurgence and the development of pathology.

Epidemiological studies have evidenced beneficial effects in humans [71], such as the prevention of degenerative diseases (e.g., cancer), cardiovascular diseases [72], neurodegenerative diseases, diabetes or osteoporosis [73].

Moreover, it has been observed that administration of BPF, hydroxytyrosol, oleuropein or resveratrol was able to attenuate the allodynia and the hyperalgesia through the removal of ROS/RNS in animal models of pain of different etiologies [19,21,31,32,54].

\section{Conclusions}

Our findings demonstrated that restoring mitochondrial functions and protecting SIRT3 activity by natural antioxidants, could be beneficial during oxidative stress-induced allodynia and hyperalgesia. Besides, re-establishing the activity of SIRT3 by BPF would be a new target in therapeutic intervention for the management and rehabilitation of pain suffering patients. 
Supplementary Materials: The following are available online at http://www.mdpi.com/2076-3921/9/11/1103/s1, Figure S1. Effects of treatment with BPF or pregabalin on allodynia and hyperalgesia after inducing CCI in rats, Figure S2. The development of hyperalgesia and allodynia coincided with an increase of 4-HNE levels either 14or 21-days post injury, Figure S3. The inhibition of SIRT3 induces acetylation on mitochondrial proteins either 14or 21-days post injury.

Author Contributions: Performed experiments: S.I., L.A.G., F.L.; Data analysis: S.I., L.A.G., F.L., V.M. (Valentina Malafoglia), M.G.; manuscript preparation: E.P., M.T., C.M., C.T.; supervision: C.M., M.T., D.S., M.F., V.M. (Vincenzo Mollace), M.A.R.; Lead to the project: C.M. All authors have read and agreed to the published version of the manuscript.

Funding: This research was funded by grants from PON03PE_00078_1, PON03PE_00078_2 and sponsored by ISAL Foundation. This study is also supported by the Italian Ministry of Health [ricerca corrente].

Conflicts of Interest: The authors declare no conflict of interest.

\section{References}

1. Treede, R.D.; Rief, W.; Barke, A.; Aziz, Q.; Bennett, M.I.; Benoliel, R.; Cohen, M.; Evers, S.; Finnerup, N.B.; First, M.B.; et al. Chronic pain as a symptom or a disease: The IASP Classification of Chronic Pain for the International Classification of Diseases (ICD-11). Pain 2019, 160, 19-27. [CrossRef] [PubMed]

2. Sommer, C.; Leinders, M.; Uceyler, N. Inflammation in the pathophysiology of neuropathic pain. Pain 2018, 159, 595-602. [CrossRef] [PubMed]

3. van Hecke, O.; Austin, S.K.; Khan, R.A.; Smith, B.H.; Torrance, N. Neuropathic pain in the general population: A systematic review of epidemiological studies. Pain 2014, 155, 654-662. [CrossRef] [PubMed]

4. Cruccu, G.; Truini, A. A review of Neuropathic Pain: From Guidelines to Clinical Practice. Pain Ther. 2017, 6, 35-42. [CrossRef] [PubMed]

5. Zhang, X.; Guan, Z.; Wang, X.; Sun, D.; Wang, D.; Li, Y.; Pei, B.; Ye, M.; Xu, J.; Yue, X. Curcumin Alleviates Oxaliplatin-Induced Peripheral Neuropathic Pain through Inhibiting Oxidative Stress-Mediated Activation of NF-kappaB and Mitigating Inflammation. Biol. Pharm. Bull. 2020, 43, 348-355. [CrossRef]

6. Doyle, T.; Chen, Z.; Muscoli, C.; Bryant, L.; Esposito, E.; Cuzzocrea, S.; Dagostino, C.; Ryerse, J.; Rausaria, S.; Kamadulski, A.; et al. Targeting the overproduction of peroxynitrite for the prevention and reversal of paclitaxel-induced neuropathic pain. J. Neurosci. 2012, 32, 6149-6160. [CrossRef]

7. Sagalajev, B.; Wei, H.; Chen, Z.; Albayrak, I.; Koivisto, A.; Pertovaara, A. Oxidative Stress in the Amygdala Contributes to Neuropathic Pain. Neuroscience 2018, 387, 92-103. [CrossRef]

8. Shim, H.S.; Bae, C.; Wang, J.; Lee, K.H.; Hankerd, K.M.; Kim, H.K.; Chung, J.M.; La, J.H. Peripheral and central oxidative stress in chemotherapy-induced neuropathic pain. Mol. Pain 2019, 15, 1744806919840098. [CrossRef]

9. Visavadiya, N.P.; Patel, S.P.; VanRooyen, J.L.; Sullivan, P.G.; Rabchevsky, A.G. Cellular and subcellular oxidative stress parameters following severe spinal cord injury. Redox Biol. 2016, 8, 59-67. [CrossRef]

10. Radi, R. Nitric oxide, oxidants, and protein tyrosine nitration. Proc. Natl. Acad. Sci. USA 2004, 101, 4003-4008. [CrossRef]

11. Salvemini, D.; Little, J.W.; Doyle, T.; Neumann, W.L. Roles of reactive oxygen and nitrogen species in pain. Free Radic. Biol. Med. 2011, 51, 951-966. [CrossRef] [PubMed]

12. Quijano, C.; Trujillo, M.; Castro, L.; Trostchansky, A. Interplay between oxidant species and energy metabolism. Redox Biol. 2016, 8, 28-42. [CrossRef] [PubMed]

13. Little, J.W.; Doyle, T.; Salvemini, D. Reactive nitroxidative species and nociceptive processing: Determining the roles for nitric oxide, superoxide, and peroxynitrite in pain. Amino Acids 2012, 42, 75-94. [CrossRef] [PubMed]

14. Fang, X.; Zhan, G.; Zhang, J.; Xu, H.; Zhu, B.; Hu, Y.; Yang, C.; Luo, A. Abnormalities in Inflammatory Cytokines Confer Susceptible to Chronic Neuropathic Pain-related Anhedonia in a Rat Model of Spared Nerve Injury. Clin. Psychopharmacol. Neurosci. 2019, 17, 189-199. [CrossRef] [PubMed]

15. Bennett, G.J.; Xie, Y.K. A peripheral mononeuropathy in rat that produces disorders of pain sensation like those seen in man. Pain 1988, 33, 87-107. [CrossRef]

16. Perrot, S. Osteoarthritis pain. Best Pract. Res. Clin. Rheumatol. 2015, 29, 90-97. [CrossRef] [PubMed]

17. Manach, C.; Donovan, J.L. Pharmacokinetics and metabolism of dietary flavonoids in humans. Free Radic. Res. 2004, 38, 771-785. [CrossRef]

18. Yu, T.; Sheu, S.S.; Robotham, J.L.; Yoon, Y. Mitochondrial fission mediates high glucose-induced cell death through elevated production of reactive oxygen species. Cardiovasc. Res. 2008, 79, 341-351. [CrossRef] 
19. Ilari, S.; Giancotti, L.A.; Lauro, F.; Dagostino, C.; Gliozzi, M.; Malafoglia, V.; Sansone, L.; Palma, E.; Tafani, M.; Russo, M.A.; et al. Antioxidant modulation of sirtuin 3 during acute inflammatory pain: The ROS control. Pharmacol. Res. 2020, 157, 104851. [CrossRef]

20. Muscoli, C.; Mollace, V.; Wheatley, J.; Masini, E.; Ndengele, M.; Wang, Z.Q.; Salvemini, D. Superoxide-mediated nitration of spinal manganese superoxide dismutase: A novel pathway in N-methyl-D-aspartate-mediated hyperalgesia. Pain 2004, 111, 96-103. [CrossRef] [PubMed]

21. Muscoli, C.; Lauro, F.; Dagostino, C.; Ilari, S.; Giancotti, L.A.; Gliozzi, M.; Costa, N.; Carresi, C.; Musolino, V.; Casale, F.; et al. Olea Europea-derived phenolic products attenuate antinociceptive morphine tolerance: An innovative strategic approach to treat cancer pain. J. Biol. Regul. Homeost. Agents 2014, 28, 105-116. [PubMed]

22. Chen, Z.; Muscoli, C.; Doyle, T.; Bryant, L.; Cuzzocrea, S.; Mollace, V.; Mastroianni, R.; Masini, E.; Salvemini, D. NMDA-receptor activation and nitroxidative regulation of the glutamatergic pathway during nociceptive processing. Pain 2010, 149, 100-106. [CrossRef]

23. Doyle, T.; Bryant, L.; Muscoli, C.; Cuzzocrea, S.; Esposito, E.; Chen, Z.; Salvemini, D. Spinal NADPH oxidase is a source of superoxide in the development of morphine-induced hyperalgesia and antinociceptive tolerance. Neurosci. Lett. 2010, 483, 85-89. [CrossRef] [PubMed]

24. Stride, N.; Larsen, S.; Hey-Mogensen, M.; Sander, K.; Lund, J.T.; Gustafsson, F.; Kober, L.; Dela, F. Decreased mitochondrial oxidative phosphorylation capacity in the human heart with left ventricular systolic dysfunction. Eur. J. Heart Fail. 2013, 15, 150-157. [CrossRef] [PubMed]

25. IASP Committee. Ethical standards for investigations of experimental pain in animals. The Committee for Research and Ethical Issues of the International Association for the Study of Pain. Pain 1980, 9, 141-143.

26. Park, E.S.; Gao, X.; Chung, J.M.; Chung, K. Levels of mitochondrial reactive oxygen species increase in rat neuropathic spinal dorsal horn neurons. Neurosci. Lett. 2006, 391, 108-111. [CrossRef]

27. Li, Y.P.; Tian, F.G.; Shi, P.C.; Guo, L.Y.; Wu, H.M.; Chen, R.Q.; Xue, J.M. 4-Hydroxynonenal promotes growth and angiogenesis of breast cancer cells through HIF-1alpha stabilization. Asian Pac. J. Cancer Prev. 2014, 15, 10151-10156. [CrossRef]

28. Uchida, K. 4-Hydroxy-2-nonenal: A product and mediator of oxidative stress. Prog. Lipid Res. 2003, 42, 318-343. [CrossRef]

29. Ayala, A.; Munoz, M.F.; Arguelles, S. Lipid peroxidation: Production, metabolism, and signaling mechanisms of malondialdehyde and 4-hydroxy-2-nonenal. Oxid Med. Cell Longev. 2014, 2014, 360438. [CrossRef]

30. Xiao, M.; Zhong, H.; Xia, L.; Tao, Y.; Yin, H. Pathophysiology of mitochondrial lipid oxidation: Role of 4-hydroxynonenal (4-HNE) and other bioactive lipids in mitochondria. Free Radic. Biol. Med. 2017, 111, 316-327. [CrossRef]

31. Lauro, F.; Ilari, S.; Giancotti, L.A.; Ventura, C.A.; Morabito, C.; Gliozzi, M.; Malafoglia, V.; Palma, E.; Paolino, D.; Mollace, V.; et al. Pharmacological effect of a new idebenone formulation in a model of carrageenan-induced inflammatory pain. Pharmacol. Res. 2016, 111, 767-773. [CrossRef]

32. Lauro, F.; Giancotti, L.A.; Ilari, S.; Dagostino, C.; Gliozzi, M.; Morabito, C.; Malafoglia, V.; Raffaeli, W.; Muraca, M.; Goffredo, B.M.; et al. Inhibition of Spinal Oxidative Stress by Bergamot Polyphenolic Fraction Attenuates the Development of Morphine Induced Tolerance and Hyperalgesia in Mice. PLoS ONE 2016, 11, e0156039. [CrossRef]

33. Galley, H.F.; McCormick, B.; Wilson, K.L.; Lowes, D.A.; Colvin, L.; Torsney, C. Melatonin limits paclitaxel-induced mitochondrial dysfunction in vitro and protects against paclitaxel-induced neuropathic pain in the rat. J. Pineal Res. 2017, 63, e12444. [CrossRef] [PubMed]

34. Chen, X.J.; Wang, L.; Song, X.Y. Mitoquinone alleviates vincristine-induced neuropathic pain through inhibiting oxidative stress and apoptosis via the improvement of mitochondrial dysfunction. Biomed. Pharmacother. 2020, 125, 110003. [CrossRef]

35. Houtkooper, R.H.; Pirinen, E.; Auwerx, J. Sirtuins as regulators of metabolism and healthspan. Nat. Rev. Mol. Cell Biol. 2012, 13, 225-238. [CrossRef]

36. Gao, J.; Zheng, Z.; Gu, Q.; Chen, X.; Liu, X.; Xu, X. Deacetylation of MnSOD by PARP-regulated SIRT3 protects retinal capillary endothelial cells from hyperglycemia-induced damage. Biochem. Biophys. Res. Commun. 2016, 472, 425-431. [CrossRef]

37. Cheng, A.; Yang, Y.; Zhou, Y.; Maharana, C.; Lu, D.; Peng, W.; Liu, Y.; Wan, R.; Marosi, K.; Misiak, M.; et al. Mitochondrial SIRT3 Mediates Adaptive Responses of Neurons to Exercise and Metabolic and Excitatory Challenges. Cell Metab. 2016, 23, 128-142. [CrossRef] 
38. Tao, R.; Coleman, M.C.; Pennington, J.D.; Ozden, O.; Park, S.H.; Jiang, H.; Kim, H.S.; Flynn, C.R.; Hill, S.; Hayes McDonald, W.; et al. Sirt3-mediated deacetylation of evolutionarily conserved lysine 122 regulates MnSOD activity in response to stress. Mol. Cell 2010, 40, 893-904. [CrossRef]

39. Lu, J.; Zhang, H.; Chen, X.; Zou, Y.; Li, J.; Wang, L.; Wu, M.; Zang, J.; Yu, Y.; Zhuang, W.; et al. A small molecule activator of SIRT3 promotes deacetylation and activation of manganese superoxide dismutase. Free Radic. Biol. Med. 2017, 112, 287-297. [CrossRef] [PubMed]

40. Kincaid, B.; Bossy-Wetzel, E. Forever young: SIRT3 a shield against mitochondrial meltdown, aging, and neurodegeneration. Front. Aging Neurosci. 2013, 5, 48. [CrossRef]

41. Tseng, A.H.; Shieh, S.S.; Wang, D.L. SIRT3 deacetylates FOXO3 to protect mitochondria against oxidative damage. Free Radic. Biol. Med. 2013, 63, 222-234. [CrossRef]

42. He, X.; Zeng, H.; Chen, J.X. Emerging role of SIRT3 in endothelial metabolism, angiogenesis, and cardiovascular disease. J. Cell Physiol. 2019, 234, 2252-2265. [CrossRef]

43. Newman, J.C.; He, W.; Verdin, E. Mitochondrial protein acylation and intermediary metabolism: Regulation by sirtuins and implications for metabolic disease. J. Biol. Chem. 2012, 287, 42436-42443. [CrossRef]

44. Park, S.H.; Ozden, O.; Jiang, H.; Cha, Y.I.; Pennington, J.D.; Aykin-Burns, N.; Spitz, D.R.; Gius, D.; Kim, H.S. Sirt3, mitochondrial ROS, ageing, and carcinogenesis. Int. J. Mol. Sci. 2011, 12, 6226-6239. [CrossRef]

45. Srivastava, S.P.; Li, J.; Kitada, M.; Fujita, H.; Yamada, Y.; Goodwin, J.E.; Kanasaki, K.; Koya, D. SIRT3 deficiency leads to induction of abnormal glycolysis in diabetic kidney with fibrosis. Cell Death Dis. 2018, 9, 997. [CrossRef]

46. Ho, L.; Wang, L.; Roth, T.M.; Pan, Y.; Verdin, E.M.; Hsiao, E.C.; Nissenson, R.A. Sirtuin-3 Promotes Adipogenesis, Osteoclastogenesis, and Bone Loss in Aging Male Mice. Endocrinology 2017, 158, 2741-2753. [CrossRef] [PubMed]

47. Muscoli, C.; Cuzzocrea, S.; Ndengele, M.M.; Mollace, V.; Porreca, F.; Fabrizi, F.; Esposito, E.; Masini, E.; Matuschak, G.M.; Salvemini, D. Therapeutic manipulation of peroxynitrite attenuates the development of opiate-induced antinociceptive tolerance in mice. J. Clin. Investig. 2007, 117, 3530-3539. [CrossRef]

48. Muscoli, C.; Dagostino, C.; Ilari, S.; Lauro, F.; Gliozzi, M.; Bardhi, E.; Palma, E.; Mollace, V.; Salvemini, D. Posttranslational nitration of tyrosine residues modulates glutamate transmission and contributes to N-methyl-D-aspartate-mediated thermal hyperalgesia. Mediators Inflamm. 2013, 2013, 950947. [CrossRef] [PubMed]

49. Muscoli, C.; Doyle, T.; Dagostino, C.; Bryant, L.; Chen, Z.; Watkins, L.R.; Ryerse, J.; Bieberich, E.; Neumman, W.; Salvemini, D. Counter-regulation of opioid analgesia by glial-derived bioactive sphingolipids. J. Neurosci. 2010, 30, 15400-15408. [CrossRef] [PubMed]

50. Rahman, I.; Chung, S. Dietary polyphenols, deacetylases and chromatin remodeling in inflammation. J. Nutrigenet. Nutrigenomics 2010, 3, 220-230. [CrossRef]

51. Parafati, M.; Lascala, A.; La Russa, D.; Mignogna, C.; Trimboli, F.; Morittu, V.M.; Riillo, C.; Macirella, R.; Mollace, V.; Brunelli, E.; et al. Bergamot Polyphenols Boost Therapeutic Effects of the Diet on Non-Alcoholic Steatohepatitis (NASH) Induced by "Junk Food": Evidence for Anti-Inflammatory Activity. Nutrients 2018, 10, 1604. [CrossRef]

52. Mollace, V.; Sacco, I.; Janda, E.; Malara, C.; Ventrice, D.; Colica, C.; Visalli, V.; Muscoli, S.; Ragusa, S.; Muscoli, C.; et al. Hypolipemic and hypoglycaemic activity of bergamot polyphenols: From animal models to human studies. Fitoterapia 2011, 82, 309-316. [CrossRef] [PubMed]

53. Wei, A.; Shibamoto, T. Antioxidant/lipoxygenase inhibitory activities and chemical compositions of selected essential oils. J. Agric. Food Chem. 2010, 58, 7218-7225. [CrossRef]

54. Mollace, V.; Ragusa, S.; Sacco, I.; Muscoli, C.; Sculco, F.; Visalli, V.; Palma, E.; Muscoli, S.; Mondello, L.; Dugo, P.; et al. The protective effect of bergamot oil extract on lecitine-like oxyLDL receptor-1 expression in balloon injury-related neointima formation. J. Cardiovasc. Pharmacol. Ther. 2008, 13, 120-129. [CrossRef]

55. Ohmichi, Y.; Ohmichi, M.; Murai, N.; Yasui, M.; Takeshita, N.; Oshibuchi, H.; Naito, M.; Nakano, T.; Sato, J. Therapeutic effects of diclofenac, pregabalin, and duloxetine on disuse-induced chronic musculoskeletal pain in rats. Sci. Rep. 2018, 8, 3311. [CrossRef]

56. Hargreaves, K.; Dubner, R.; Brown, F.; Flores, C.; Joris, J. A new and sensitive method for measuring thermal nociception in cutaneous hyperalgesia. Pain 1988, 32, 77-88. [CrossRef]

57. Weir, H.J.; Lane, J.D.; Balthasar, N. SIRT3: A Central Regulator of Mitochondrial Adaptation in Health and Disease. Genes Cancer 2013, 4, 118-124. [CrossRef] 
58. Ozden, O.; Park, S.H.; Kim, H.S.; Jiang, H.; Coleman, M.C.; Spitz, D.R.; Gius, D. Acetylation of MnSOD directs enzymatic activity responding to cellular nutrient status or oxidative stress. Aging 2011, 3, $102-107$. [CrossRef]

59. Rayment, C.; Hjermstad, M.J.; Aass, N.; Kaasa, S.; Caraceni, A.; Strasser, F.; Heitzer, E.; Fainsinger, R.; Bennett, M.I.; European Palliative Care Research Centre. Neuropathic cancer pain: Prevalence, severity, analgesics and impact from the European Palliative Care Research Collaborative-Computerised Symptom Assessment study. Palliat. Med. 2013, 27, 714-721. [CrossRef]

60. Malafoglia, V.; Celi, M.; Muscoli, C.; Ilari, S.; Lauro, F.; Giancotti, L.A.; Morabito, C.; Feola, M.; Tarantino, U.; Raffaeli, W. Lymphocyte opioid receptors as innovative biomarkers of osteoarthritic pain, for the assessment and risk management of opioid tailored therapy, before hip surgery, to prevent chronic pain and opioid tolerance/addiction development: OpMarkArt (Opioids-Markers-Arthroprosthesis) study protocol for a randomized controlled trial. Trials 2017, 18, 605. [PubMed]

61. Raffaeli, W.; Malafoglia, V.; Bonci, A.; Tenti, M.; Ilari, S.; Gremigni, P.; Iannuccelli, C.; Gioia, C.; Di Franco, M.; Mollace, V.; et al. Identification of MOR-Positive B Cell as Possible Innovative Biomarker (Mu Lympho-Marker) for Chronic Pain Diagnosis in Patients with Fibromyalgia and Osteoarthritis Diseases. Int. J. Mol. Sci. 2020, 21, 1499. [CrossRef]

62. Ye, L.; Xiao, L.; Bai, X.; Yang, S.Y.; Li, Y.; Chen, Y.; Cui, Y.; Chen, Y. Spinal mitochondrial-derived ROS contributes to remifentanil-induced postoperative hyperalgesia via modulating NMDA receptor in rats. Neurosci. Lett. 2016, 634, 79-86. [CrossRef]

63. Areti, A.; Yerra, V.G.; Naidu, V.; Kumar, A. Oxidative stress and nerve damage: Role in chemotherapy induced peripheral neuropathy. Redox Biol. 2014, 2, 289-295. [CrossRef]

64. Areti, A.; Yerra, V.G.; Komirishetty, P.; Kumar, A. Potential Therapeutic Benefits of Maintaining Mitochondrial Health in Peripheral Neuropathies. Curr. Neuropharmacol. 2016, 14, 593-609. [CrossRef]

65. Sui, B.D.; Xu, T.Q.; Liu, J.W.; Wei, W.; Zheng, C.X.; Guo, B.L.; Wang, Y.Y.; Yang, Y.L. Understanding the role of mitochondria in the pathogenesis of chronic pain. Postgrad. Med. J. 2013, 89, 709-714. [CrossRef]

66. Sun, W.; Liu, C.; Chen, Q.; Liu, N.; Yan, Y.; Liu, B. SIRT3: A New Regulator of Cardiovascular Diseases. Oxid. Med. Cell Longev. 2018, 2018, 7293861. [CrossRef]

67. Shao, H.; Xue, Q.; Zhang, F.; Luo, Y.; Zhu, H.; Zhang, X.; Zhang, H.; Ding, W.; Yu, B. Spinal SIRT1 activation attenuates neuropathic pain in mice. PLoS ONE 2014, 9, e100938. [CrossRef]

68. Yu, S.; Zhou, X.; Xiang, H.; Wang, S.; Cui, Z.; Zhou, J. Resveratrol Reduced Liver Damage After Liver Resection in a Rat Model by Upregulating Sirtuin 1 (SIRT1) and Inhibiting the Acetylation of High Mobility Group Box 1 (HMGB1). Med. Sci. Monit. 2019, 25, 3212-3220. [CrossRef]

69. Pan, M.H.; Koh, Y.C.; Lee, T.L.; Wang, B.; Chen, W.K.; Nagabhushanam, K.; Ho, C.T. Resveratrol and Oxyresveratrol Activate Thermogenesis via Different Transcriptional Coactivators in High-Fat Diet-Induced Obese Mice. J. Agric. Food Chem. 2019, 67, 13605-13616. [CrossRef] [PubMed]

70. Zhang, L.; Xue, H.; Zhao, G.; Qiao, C.; Sun, X.; Pang, C.; Zhang, D. Curcumin and resveratrol suppress dextran sulfate sodiuminduced colitis in mice. Mol. Med. Rep. 2019, 19, 3053-3060. [PubMed]

71. Arts, I.C.; Hollman, P.C. Polyphenols and disease risk in epidemiologic studies. Am. J. Clin. Nutr. 2005, 81, 317S-325S. [CrossRef] [PubMed]

72. Manach, C.; Scalbert, A.; Morand, C.; Remesy, C.; Jimenez, L. Polyphenols: Food sources and bioavailability. Am. J. Clin. Nutr. 2004, 79, 727-747. [CrossRef]

73. Scalbert, A.; Johnson, I.T.; Saltmarsh, M. Polyphenols: Antioxidants and beyond. Am. J. Clin. Nutr. 2005, 81, 215S-217S. [CrossRef]

Publisher's Note: MDPI stays neutral with regard to jurisdictional claims in published maps and institutional affiliations. 